\title{
Legacy Scholars II: The 2021 Nominations
}

The concept of "Legacy Scholars" as a special issue series was originally developed by the International Journal of Gender and Entrepreneurship (IJGE) at one of our editorial meetings in London. Led by IJGE Consulting Editor Dr Kate Lewis, the series was launched in 2020 with the special issue: Celebrating a Decade of Research in Gender and Entrepreneurship: The Legacy Special Issue. This vehicle was appropriate for our core objectives - platforming eminent research scholars in the field while also reaching out to the next generation of excellent scholars by way of building a legacy of research scholarship. Hence, for our first legacy special issue, we invited established eminent gender and entrepreneurship scholars to submit papers that reflected on the developments within the field through their personal lens and then to nominate young talented scholars whose work would be platformed in a subsequent legacy special issue. The 2020 eminent scholars (Vol. 12, Issue 1) included Professors Brush, Greene, Welter, Marlow, Hughes, Jennings, Watson, Holmquist, Sundin and Nelson. We are extremely grateful to these leading lights for not only sharing their research insights with the IJGE community by allowing us to publish their scholarly contributions but also for taking the time to pass the baton to the next generation by offering their personal nominations for the subsequent legacy special issue; it is the work of these young scholars that we platform here. Consistent with our original intention to build a legacy of gender and entrepreneurship scholarship, we will be reaching out to the 2021 scholars to offer their nominations for the legacy special issue III.

But let us return to our current focus and the gender and entrepreneurship scholarship we are celebrating in this issue. We begin with a paper by Angela Martinez Dy, a scholar nominated by Professor Susan Marlow. In her paper - "Doing One's Work' in Entrepreneurship Studies: Interpellation, Distraction, Disruption and Transformation" - Martinez Dy reflects on her experiences as an early career scholar of gender and entrepreneurship. She adopts the view that "the personal is political" and offers - from her own experience-vital context for assessing the contribution of her work and paving out a future research agenda. Through reflecting on her positionality, philosophical and political commitments and theorizing from her experience of racist distraction and intersectional marginality in contemporary academia, she is able to explore the implications for aspiring gender and entrepreneurship scholars. Martinez Dy posits that continuing to challenge racism in academia and scholarship allows us to enrich our own intellectual and affectual experiences of academic work and generate an expansive legacy of critical scholarship. Given that everyone has different experiences in their academic career, it must be acknowledged that not all of Martinez Dy's sentiments will resonate with scholars; we all process experiences through our own individual lens. That said, what this paper does is to open the potential to create positive social change by calling on the academic community to recognize the value of individual contributions to shaping a liveable, equitable and imaginative academic future.

In their comparative study - "Gender role (in-)congruity and resource-provider gender biases: A conceptual model" - Vartuhi Tonoyan and Robert Strohmeyer focus on male/female start-ups (Tonoyan was nominated as a Legacy Scholar by Professors Karen Hughes and Jennifer Jennings). The authors set out to develop a more nuanced and integrative approach to studying gender biases in entrepreneurial resource provision, mindful that the literature evidences both positive and negative discrimination against female entrepreneurs in this regard. Their conceptual model explores whether, how and when entrepreneurial resourceproviders are likely to under-, over- and equivalue female-led innovative ventures relative to equivalent male-led innovative ventures. The gender-typing of the entrepreneur's core

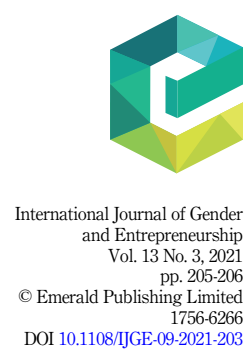


IJGE

13,3

206

product/service offering is considered as a key contingency factor likely to moderate the proposed relationship. The authors also identify first- and second-order mediating mechanisms that underlie the relationship between evaluations of the founder-CEO, his/ her venture attractiveness and the provision of resources to their start-up ventures. In doing so, Tonoyan and Strohmeyer advance extant scholarship on the role of gender stereotypes for women's employment and advancement opportunities in paid work - scholarship that has traditionally viewed entrepreneurship as the solution for women fleeing the corporate world to advance careers.

Nominated as a Legacy Scholar by Professors Elisabeth Sundin and Carin Holmquist, Caroline Wigren-Kristoferson's paper with Maria Aggestam focuses on "Exploring the masculinization of innovation practice within a municipality." The authors construct an empirically informed theoretical framework to analyze the relationship between gender and innovation in the context of a Swedish municipality. Drawing on an ethnographic study employing "shadowing" techniques as method of observation and analyzing their three illustrative tales from a feminist perspective, they manage to provide a more balanced approach to the conceptualization of gendered ascriptions relating to outcomes of innovation work. Analysis of findings reveals how the complexities of a gendered work life within a municipality can create paradoxes. The paper helps deepen understanding of gender paradoxes in the public sector and recognizes innovation as being masculine gendered within the feminine context.

The final paper in this legacy special issue is by Christina Constantinidis - a scholar nominated by Professor Teresa Nelson. In "How female entrepreneurs build strong business relationships: The power of gender stereotypes", Constantinidis explores women entrepreneurs' networking activities. She posits that more processual and contextual understandings of business network relationships are needed in order to capture relational and cognitive dimensions and highlight the potential of strong ties for female entrepreneurs. According to Constantinidis, research needs to "zoom into" the social interactions and mutual relationships that constitute the core of social network building. Accordingly, the study she presents in this paper investigates how - over time and at the micro level - female entrepreneurs build and develop strong interpersonal business relationships based on mutual trust and shared identity. Adopting a feminist constructionist perspective (i.e. "doing gender"), she explores how gender perceptions and expressions permeate mutual interactions and help shape strong business relationships. Breaking the tradition of focusing on barriers and challenges to female entrepreneurs' networking activities, Constantinidis' qualitative, longitudinal case study illustrates how female entrepreneurs can use gender stereotypes as a resource, enacting the ideas of social feminism in their entrepreneurial practice, and thus challenging traditional gender stereotypes. The author contributes to extant scholarship by providing an extension to social network theory in women's entrepreneurship.

Collectively, the 2021 Legacy Scholars' contributions challenge existing notions in current literature studies in relation to racism, start-up ventures, innovation and networking in the context of gender and entrepreneurship. The insights they provide through their empirical investigations, analyses, personal reflections and unique experiences offer opportunities for further debate, as well as further challenge. In doing so, they signal toward an exciting new research agenda upon which future scholars in this field can build by applying their own critical lenses. We look forward to hearing from these future scholars in "Legacy III."

Kate Lewis

Newcastle University Business School, Newcastle University, Newcastle upon Tyne, UK, and

Colette Henry

School of Business and Humanities, Dundalk Institute of Technology, Dundalk, Ireland and Department of Business Innovation and Strategy, Griffith University, Queensland, Australia 